\title{
Coagulation Using Kerosene for Magnetic Deinking of Waste Office Paper*1
}

\author{
Tatsuya $\mathrm{Oki}^{1}$, Shuji Owada ${ }^{2}$, Hiroki Yotsumoto ${ }^{1}$, Hirokazu Tanuma $^{3, * 2}$ and Yuu Takeuchi ${ }^{3, * 3}$ \\ ${ }^{1}$ Particle Separation Group, Research Institute of Green Technology, National Institute of Advanced Industrial Science and Technology, \\ Tsukuba 305-8569, Japan \\ ${ }^{2}$ Department of Resources and Environmental Engineering, Science and Engineering, Waseda University, Tokyo 169-8555, Japan \\ ${ }^{3}$ Mineral Resources Engineering Specialization, Major in Mineral Resources Engineering and Materials Science and Engineering, \\ Graduate School of Waseda University, Tokyo 169-8555, Japan
}

\begin{abstract}
A method for disintegrating waste office paper using kerosene was reported in our previous paper, which achieved almost a $100 \%$ liberation of toner from paper fibers. The liberated toner must be completely separated to realize effective deinking. Recently, a new method for deinking waste officer paper by magnetic separation after hetero-coagulation of magnetic and non-magnetic toner by 1-octadecanol was reported by Augusta et al. Under this method, coagulation was carried out at $72^{\circ} \mathrm{C}$. The 1 -octadecanol liquid was then cooled to produce strong solid coagulates. As reported in our previous paper, kerosene has the ability to soften toner, and strong coagulates for magnetic separation may be produced by their adhesion when used as a flocculant. The present study investigated the size of toner particles liberated by the kerosene disintegration method, and compared the bonding strength between the toner particles coagulated by the addition of kerosene as a flocculant to those coagulated with 1-octadecanol. After these investigations, the coagulating and deinking properties of kerosene and 1-octadecanol were compared by rejecting toner coagulates with a neodymium-boron magnet. The results showed that nearly perfect deinking can be achieved with little paper loss, even in ambient temperature, due to the large and strong coagulates produced by this method. When kerosene was used in the disintegration and coagulation stages, the average coagulate size was $1114 \mu \mathrm{m}$, and a deinking percentage of $98.4 \%$ was attained through separation with a neodymium-boron magnet.
\end{abstract}

(Received June 21, 2002; Accepted November 8, 2002)

Keywords: paper recycling, office paper, deinking, toner, kerosene, coagulation, magnetic separation

\section{Introduction}

The amount of waste office paper produced by photocopying machines and laser printers is gradually increasing. ${ }^{1)}$ Most waste office paper is assumed to be regenerated as highgrade paper because of its high quality and whiteness. However, the rate of waste office paper regeneration has not increased. ${ }^{1)}$ One of the sources of this problem is the difficulty of liberating toner from paper fibers; another is the difficulty of removing the toner so that no specks remain on the paper. The former problem exists because, unlike with conventional oil-based ink, toner cannot be saponificated in alkali solution. In conventional studies, toner liberation has been promoted by various methods of comminuting waste office paper into fine particles. However, these are not ideal separation methods because paper fibers also get cut in the processes. ${ }^{2}$ A disintegration method for waste office paper using kerosene was investigated in our previous paper. $\left.{ }^{2}\right) \mathrm{We}$ reported a toner liberation of almost $100 \%$ without cutting the paper fibers, even under weak stirring conditions, by soaking the paper in alkali and kerosene before disintegration. However, toner specks, which are a source of trouble in the separation stage, are visible black spots more than $30 \mu \mathrm{m}$ remain on regenerated paper. Their existence hampers the distribution of high-grade regenerated paper, such as office paper.

It is within these parameters that separation methods to decrease toner specks have been reported, most utilizing flotation. ${ }^{3)}$ From the context that complete removal of toner

\footnotetext{
*1 This Paper was Originally Published in Japanese in Journal of the Mining and Materials Processing Institute of Japan 118, No. 3, 4 (2002).

${ }^{* 2}$ Graduate Student, Waseda University. Present address: Keihin Corporation, Kakuda 981-1581, Japan.

${ }^{* 3}$ Graduate Student, Waseda University.
}

specks is impossible by flotation, methods such as positively changing the properties of toner particles rather hydrophilic than hydrophobic, have been investigated actively in the waste paper industry. ${ }^{4-7)}$ Although this method may not increase the deinking percentage, it could potentially suppress the creation of toner specks. Toner would thus remain on regenerated paper as fine particles, since toner coagulation could be checked in the flotation cell. However, this system of recycling waste office paper has not yet been implemented because toner specks cannot be completely removed by flotation, even under various conditions.

Recently, a new deinking method by magnetic separation has been examined. ${ }^{8-10)}$ It was anticipated that magnetic separation would decrease the incidence of toner specks because it easily separates particles over several hundred micrometers in size. Such particles are not removed easily by flotation. There are two classifications of toner; magnetic, which contains magnetic powder, and non-magnetic, which does not contain any magnetic powder. Gubitz et al. ${ }^{8)}$ reported a $92.7 \%$ deinking percentage for magnetic toner when magnetic separation was conducted after enzymatic treatment. Furthermore, Augusta et al. ${ }^{9,10)}$ reported a magnetic separation method for waste office paper containing both magnetic and non-magnetic toner by coagulating both toners together. The selection of a flocculant that produces large and strong coagulates is especially important for this method. If the coagulation bonding strength is weak, coagulates will break, and only magnetic toner would be recovered. Moreover, small-diameter coagulates would be carried away by the flow of fluid and not be recovered by a magnet if their content of magnetic toner was low. ${ }^{9)}$ So by using 1-octadecanol, whose melting point is $60^{\circ} \mathrm{C}$, as a flocculant, Augusta et al. produced coagulates at $72^{\circ} \mathrm{C}$ and cooled it down to ambient temperature to solidify the 
flocculants. Strong coagulates averaging $120.5 \mu \mathrm{m}$ in size were produced by this method and separated by a magnetic separator with a magnetic flux density of $0.3 \mathrm{~T}$. The results showed that only $7 \%$ of paper fiber was lost and that a deinking percentage of $90.8 \%$ was attained. However, this process, which lowers the liquid to ambient temperature right after raising it to $72^{\circ} \mathrm{C}$ requires further examination in terms of energy consumption.

A method to soften toner with kerosene was investigated in our previous paper, ${ }^{2)}$ which resulted in a high degree of toner liberation by weak stirring. As the adhesion of toner increases slightly by kerosene soaking, there is a possibility that strong coagulates could be produced even at ambient temperature. This paper examines the bonding strength of toner softened by kerosene and the application of kerosene as a flocculant for the coagulation and magnetic deinking method.

\section{Experimental}

\subsection{Sample}

Toner is classified by whether or not it contains magnetic powder and by the kinds of resin from which it is composed. Magnetic toner made of styrene-acrylic resin (Canon: CRGEPKS II, resin content: about $40 \%$ ), and non-magnetic toner made of multiple resin containing polyester resin (FujiXerox: D282, resin content: about 90\%), were used as toner samples in this study, as in our previous paper. ${ }^{2)}$ The magnetic toner's magnetic powder content was estimated to be $58 \%$ from the quantitative results of an ICP analysis of iron. The size distributions of both toner samples were measured by a continuous flow image analyzer (Nireco: Luzex SE-SPL). The $50 \%$ diameter by volume of both samples was $8.7 \mu \mathrm{m}$ for the magnetic and $15.3 \mu \mathrm{m}$ for the non-magnetic toner, respectively. The model waste paper samples were prepared by printing 100 black circles (11 point font) on one side of A4 photocopy paper (NBC-Ricoh:902218, $65 \mathrm{~g} / \mathrm{m}^{2}$ ) with a laser printer (Canon: Laser Shot B406E) using magnetic toner samples at first. Next, a copy of this printed paper was made on the same type of A4 paper with a photocopying machine (Fuji-Xerox: Vivace 720) using non-magnetic toner. Then, these two pieces of printed paper were cut into $50 \mathrm{~mm} \times 50 \mathrm{~mm}$ pieces (Fig. 1) weighing $0.15 \mathrm{~g}$ and used as model waste paper for experimentation.

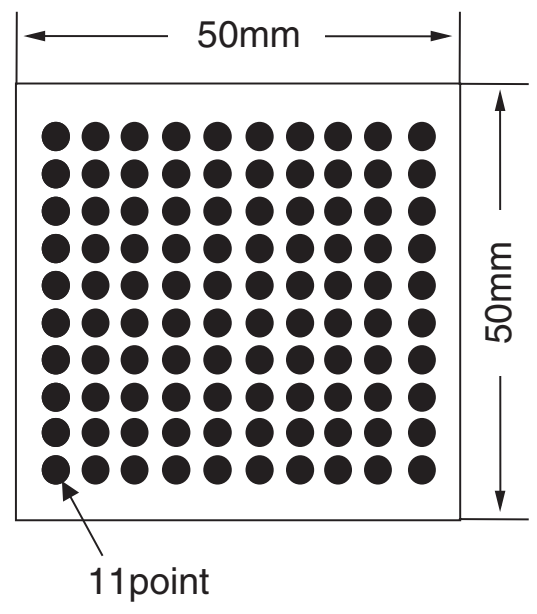

Fig. 1 Illustration of model waste paper sample.

\subsection{Experimental methods}

\subsubsection{Disintegration of model waste paper sample}

Disintegration of a model waste paper sample was conducted by the kerosene disintegration method based on the results of our previous paper. ${ }^{2)}$ A model sample $(0.15 \mathrm{~g})$ was washed with de-ionized water after being soaked in $100 \mathrm{~mL}$ of $8 \%$ sodium hydroxide solution for $12 \mathrm{~h}$. This sample was then put into a $1 \%$ kerosene emulsion, which had been emulsified with a disperser (Yamato: LK-21) at $333.3 \mathrm{~s}^{-1}$ for $1 \mathrm{~min}$ and soaked for $30 \mathrm{~min}$, while being stirred at $2 \mathrm{~s}^{-1}$ by a stainless impeller (rotation diameter: $50 \mathrm{~mm}$ ). Although the paper kept its prototype without disintegrating and the toner peeling off, the toner softened and the wedged particles infiltrating the paper fibers became easier to remove. After washing in $100 \mathrm{~mL}$ of $8 \%$ sodium hydroxide solution and stirring by impeller at $8.3 \mathrm{~s}^{-1}$ for $5 \mathrm{~min}$, a disintegrated sample was obtained with the toner liberated. The $0.15 \%$ pulp concentration of was used in all experiments.

\subsubsection{Measurement of printed toner thickness}

The appearance of printed toner and toner liberated by the kerosene disintegration method was observed through a microscope. The model waste paper samples were used to observe printed toner; liberated toner was observed on a glass plate $(18 \mathrm{~mm} \times 24 \mathrm{~mm})$. The thicknesses of the toner on copy paper and overhead projector transparency (Gakushu-kenkyusha, No. 87241), each respectfully printed with a laser printer and a photocopying machine (i.e., four different samples), were measured with a digital micrometer (Mitsutoyo: MDC-25M; diameter of measurement area: $\phi 6.34 \mathrm{~mm}$ ). The values were calculated from the difference between the printed and non-printed parts. The border between the unprinted paper and toner was observed by SEM, and the difference in height between them was measured by AFM (JEOL: JSPM-4200) to confirm the characteristics of the printed model waste paper sample. Measurements by AFM were carried out in contact mode (measurement area: $60 \mu \mathrm{m} \times 60 \mu \mathrm{m})$.

\subsubsection{Measurement of size distribution of toner}

Toner particle size was measured after a model waste paper sample printed with magnetic toner was disintegrated so that it could be easily recovered by a magnet. The disintegrated suspension was put into a $300 \mathrm{~mL}$ beaker and stirred slowly so that the sample would disperse. Toner was then recovered with a $\phi 30 \mathrm{~mm}(0.45 \mathrm{~T})$ neodymium-boron magnet. The recovered toner was placed on a microscope and its image was fed into a personal computer through a video camera in order to measure the area of each toner particle by image analysis software (Mitani: Winroof). Although the Heywood diameter calculated from this area was shown as the toner size based on the area in our previous paper, ${ }^{2)}$ this would have lead to large errors when toner from disintegrated samples is compared to toner before being printed because the shape of the former is flat and the latter is irregular. So, sphere-equivalent volume was calculated from the Heywood diameter for toner before being printed. In the case of toner from the disintegrated samples, the area calculated by image analysis was converted to volume by multiplying the area by the toner thickness obtained in 2.2.2. The sphere-equivalent diameter was then calculated based on this volume. All size 
distributions in this study are shown based on volume.

\subsubsection{Measurement of toner bonding strength}

Pulling stress was measured by a tackiness tester (Malcom: TK-1) after magnetic and non-magnetic toner contacted each other, which corresponds to the bonding strength between the two kinds of toner. Measurements were carried out following method JIS Z3284, which outlines an adhesion measurement for solder paste. To make a $3 \mathrm{~mm}$ tablet sample, $0.3 \mathrm{~g}$ of magnetic and non-magnetic toner samples before being printed were pressed by a hydraulic press at $20 \mathrm{MPa}$ for $5 \mathrm{~min}$ using a $\phi 10 \mathrm{~mm}$ tablet cell. The surfaces of both tablet samples were glossy and smooth, even without being polished. A sample tablet of magnetic toner was glued to the tip of the tackiness tester's stainless probe (column shape: $\phi 5.1 \mathrm{~mm}$ ) and that of non-magnetic toner was glued to the bottom of a $25 \mathrm{~mL}$ weighting bottle, which was set to a tackiness tester. The weighting bottle was then filled with either $10 \mathrm{~mL}$ of kerosene emulsion or 1-octadecanol emulsion of several concentrations so that the contact side of both samples would soak as shown in Fig. 2(a). Following the examinations of Augusta et al., ${ }^{9)}$ in the case of using 1octadecanol, the tablet samples were soaked for $30 \mathrm{~min}$ in emulsions, which were kept at $70^{\circ} \mathrm{C}$ by a heater. To stir the emulsion, a small amount $\left(3 \times 10^{-6} \mathrm{~m}^{3} / \mathrm{s}\right)$ of air was blown obliquely down onto the surface of the emulsion tangentially from the weighing bottle because mechanical stirring was difficult for this experiment. Both samples were put under a force of $0.157-0.549 \mathrm{~N}$ for $1 \mathrm{~min}$ immediately after being soaked. While under pressure, the emulsion was rapidly cooled down to $20^{\circ} \mathrm{C}$ by spraying a coolant around the weighing bottle to solidify the 1-octadecanol, and the pulling stress at $2.0 \mathrm{~mm} / \mathrm{s}$ pulling speed was measured (Fig. 2(b)). For the measurements in kerosene, pressing time, pressing force, and pulling velocity were the same as for 1octadecano; temperature, however, was fixed at $20^{\circ} \mathrm{C}$.

\subsubsection{Coagulation and magnetic deinking of disintegra- ted sample}

After disintegrating each model waste paper sample of magnetic and non-magnetic toner (total: $0.3 \mathrm{~g}$ ) by the method outlined in 2.2.1, they were coagulated to each other by stirring in a $200 \mathrm{~mL}$ beaker the disintegrated samples into $100 \mathrm{~mL}$ of kerosene or 1-octadecanol emulsion. Concentrations of the emulsions were $0.02 \%, 1 \%$, and $50 \%$ for kerosene and $0.02 \%$ for 1 -octadecanol. Taking into account

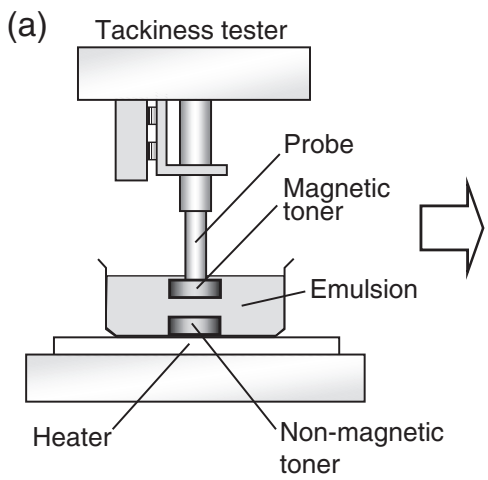

(b)

Fig. 2 Measurement of pulling stress between magnetic and non-magnetic toner samples. the coagulation properties during stirring, 50\% kerosene was used here instead of non-diluted kerosene. Although the details of coagulation conditions were not identified in Augusta et al.'s paper, ${ }^{9)}$ the impeller revolution and stirring time was assumed to be $3 \mathrm{~s}^{-1}$ and $15-45 \mathrm{~min}$, respectively, based on the study by Synder et al. ${ }^{13)}$ So, coagulation experiments were carried out in the present study at $3 \mathrm{~s}^{-1}$ for $45 \mathrm{~min}$ by the same impeller used in 2.2.1. After stirring, coagulate sizes were calculated by converting their Heywood diameters, which had been measured by image analysis (to 2.2.3), to sphere-equivalent volume.

Separation was carried out by the neodymium-boron magnet used in 2.2.3. This magnet contacted all coagulates in the suspension - without putting any of its weight on them - through a $150 \mu \mathrm{m}$ thick glass film after coagulation. Then, the magnet together with the glass plate was picked up and coagulates attracted by the magnet over the glass were recovered by washing them off with water. The same kind of magnetic separation was carried out once more on these recovered coagulates. Coagulates that were twice recovered by magnet were grouped as a magnetic product; all of the others were grouped as a non-magnetic product. Sphereequivalent volumes of the magnetic and a non-magnetic products were obtained by the same method as mentioned above, and the deinking percentage by volume was calculated.

\section{Results and Discussion}

\subsection{Shapes and sizes of toner after kerosene disintegra- tion}

Making large coagulates is necessary to recover as much toner as possible by magnet in the coagulation and magnetic deinking process. ${ }^{9)}$ Knowing the feed size is important to evaluate the sizes of coagulates made under various coagulation conditions. To know the exact size of a toner particle, it is necessary to measure its area and thickness because toner liberated by kerosene forms a flat shape., ${ }^{2,11,12)}$ Although area could be measured by image analysis, measuring thickness is more difficult. Figure 3 shows microscopic images of printed toner (a) and toner liberated by the kerosene disintegration method (b), from the point of view of the thickness of the paper. Each image is actually made up of a combination of five separate images, each one focusing on a point at a particular depth in the original image. These figures are for non-magnetic toner, whose appearance differs from that of magnetic toner only slightly. Since the surface of printed toner appears gritty because of coagulated particles, the thickness cannot be estimated. On the other hand, liberated toner has a glossy and billowy smooth surface. Kerosene soaking is considered to change the toner into a softened state. The thickness of the non-magnetic toner was estimated to be about $10 \mu \mathrm{m}$ (the thickness in Fig. 3(b)) from the shape of the end. The thickness of the magnetic toner seemed to be slightly thinner than that of the nonmagnetic toner. In this way, it would be difficult to measure the thickness of liberated toner directly by a micrometer or probe-microscope because it has a wavy surface and the bottom is not glued onto the glass plate, as has been found by reflected images. So, the thickness of the printed toner was 


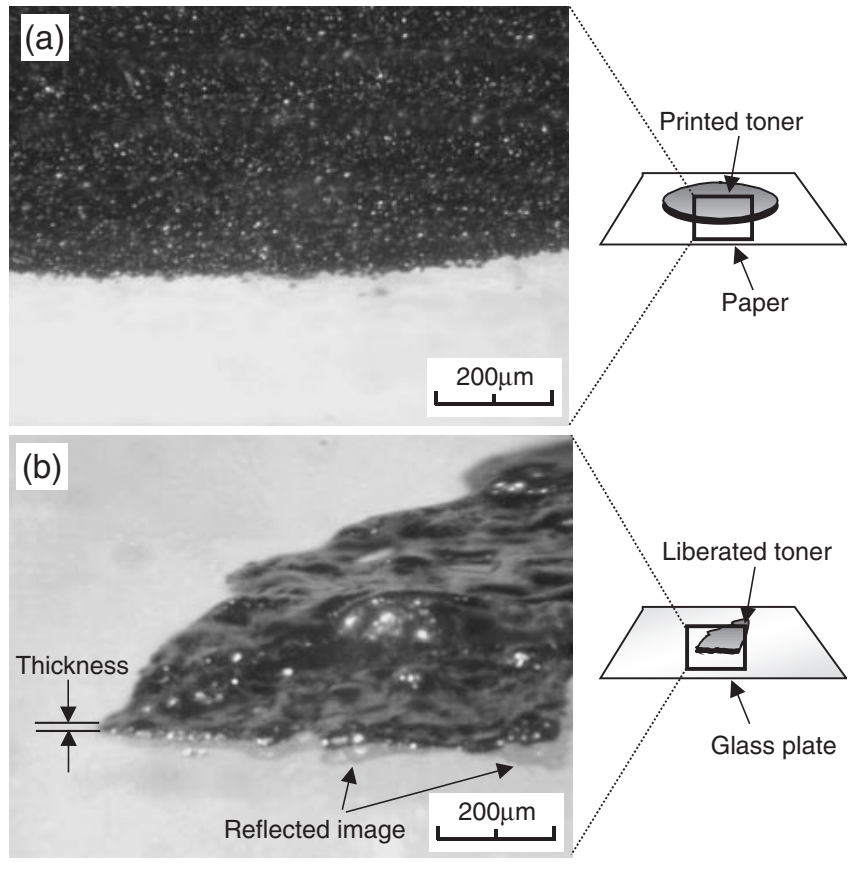

Fig. 3 Microscopic images of printed and liberated non-magnetic toner (viewed from thickness direction). (a) printed toner (model waste paper sample). (b) liberated toner (liberated by kerosene disintegration method).

Table 1 Thickness of printed toner.

\begin{tabular}{|c|c|c|c|c|}
\hline \multirow{4}{*}{$\begin{array}{l}\text { Measuring } \\
\text { parts }\end{array}$} & \multicolumn{2}{|c|}{ On paper } & \multicolumn{2}{|c|}{ On transparency } \\
\hline & & Difference & & Difference \\
\hline & Thickness & of thickness* & Thickness & of thickness* \\
\hline & $D / \mu \mathrm{m}$ & $\Delta D / \mu \mathrm{m}$ & $D / \mu \mathrm{m}$ & $\Delta D / \mu \mathrm{m}$ \\
\hline Non-printed & $\begin{array}{l}89.5 \\
(\mathrm{~s}=1.9)\end{array}$ & - & $\begin{array}{l}104.4 \\
(\mathrm{~s}=1.3)\end{array}$ & - \\
\hline $\begin{array}{l}\text { Printed with } \\
\text { magnetic toner }\end{array}$ & $\begin{array}{l}93.4 \\
(\mathrm{~s}=2.0)\end{array}$ & 3.9 & $\begin{array}{l}109.0 \\
(\mathrm{~s}=0.9)\end{array}$ & 4.6 \\
\hline $\begin{array}{l}\text { Printed with } \\
\text { non-magnetic toner }\end{array}$ & $\begin{array}{l}95.8 \\
(s=1.7)\end{array}$ & 6.3 & $\begin{array}{l}112.5 \\
(\mathrm{~s}=0.8)\end{array}$ & 8.1 \\
\hline
\end{tabular}

* Difference of thickness between printed and non-printed parts.

s: Standard deviation.

investigated in detail and compared to that of a microscopic image (Fig. 3(b)).

To calculate the actual thickness of the toner, the thickness at the printed part and non-printed area of paper or transparency that had been printed by either magnetic or non-magnetic toner were first measured by a digital micrometer. The differences were calculated as the thickness of printed toner. The results are shown in Table 1. The average value of measurements taken at 30 different points is shown. In the case of printing to paper, the difference in thickness between printed and non-printed parts was $3.9 \mu \mathrm{m}$ for magnetic toner and $6.3 \mu \mathrm{m}$ for non-magnetic toner. When printed on a transparency, the difference was $4.6 \mu \mathrm{m}$ for magnetic toner and $8.1 \mu \mathrm{m}$ for non-magnetic toner. Printed toner on paper was classified into the upper part on paper and the wedged part that infiltrated the paper fiber as shown in Fig. 4. As toner does not infiltrate a transparency, the thickness is considered to be the sum of both parts; i.e., the total thickness of printed toner. The difference between the

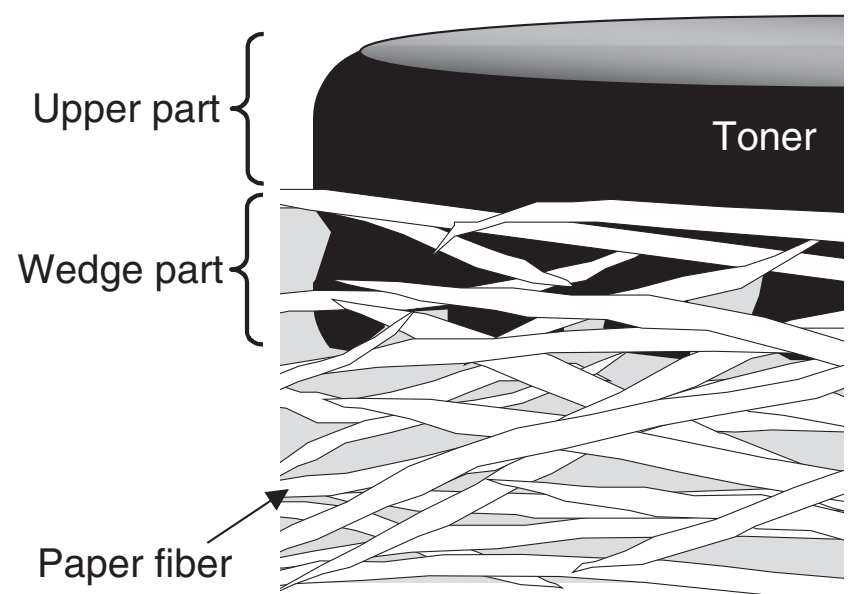

Fig. 4 Illustration of printed toner.

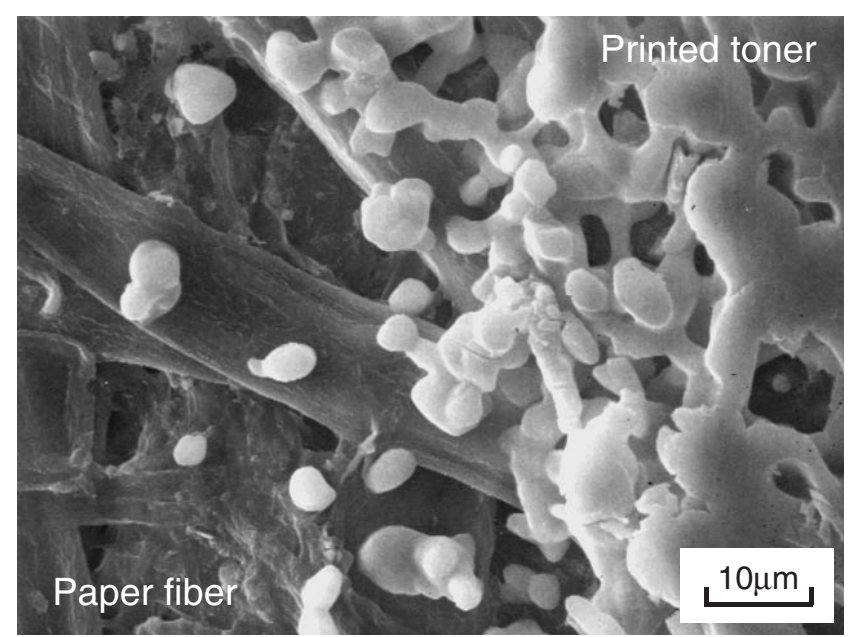

Fig. 5 SEM image of the border of paper and magnetic toner on a model waste paper sample.

toner thickness on paper and transparency was estimated to be the thickness of the wedged part that infiltrated the paper fiber. That thickness was $0.7 \mu \mathrm{m}$ for magnetic toner and $1.8 \mu \mathrm{m}$ for non-magnetic toner. The thickness of printed toner (magnetic: $4.6 \mu \mathrm{m}$, non-magnetic: $8.1 \mu \mathrm{m}$ ) approximated that of the liberated toner observed in Fig. 3(b).

On the other hand, these printed toner thicknesses are so thin that they do not even reach particle size at $50 \mathrm{vol} \%$ of toner before being printed (magnetic toner: $8.7 \mu \mathrm{m}$, nonmagnetic toner: $15.3 \mu \mathrm{m}$ ). So, the borderline of printed and non-printed areas of a model waste paper sample was observed by SEM to confirm the state of printed toner. Figure 5 shows an SEM image of magnetic toner on a sample. Although some toner about $10 \mu \mathrm{m}$ in diameter can be observed on the printed area, much of the toner has been flattened by the heat from printing. Figure 6 shows an AFM image of the border. The depth profiles show that the difference between the upper part on paper and the toner surface is about $4 \mu \mathrm{m}$, which corresponds with the measurements taken by a digital micrometer $(3.9 \mu \mathrm{m})$. Therefore, the measurements by micrometer seem to indicate the exact 


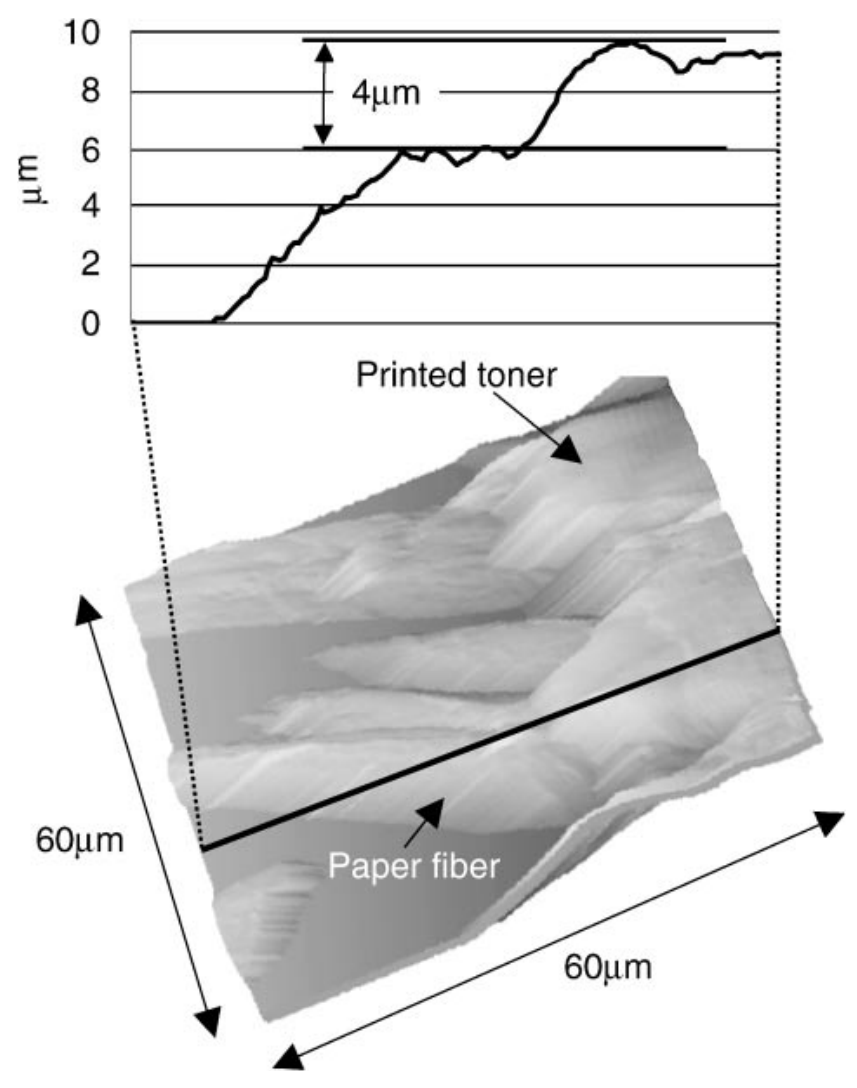

Fig. 6 AFM image and profile for depth direction around the border of paper and magnetic toner on a model waste paper sample.

thickness of toner in its printed state. From the results, it has been shown that the thickness of toner liberated by kerosene and that of printed toner is almost the same, although they appear different. In what follows, the value of $4.6 \mu \mathrm{m}$, which was measured in 3.1 , will be regarded as the thickness of magnetic toner resulting from disintegration treatments.

Next, using a model sample printed with magnetic toner, the areas of printed toner (black circles) and toner after being disintegrated using 1\% kerosene emulsion and undiluted kerosene were measured and then converted to volume by multiplying it by the toner thickness obtained in 2.2. This value for volume was then used to calculate the sphereequivalent diameter. The Heywood diameter was directly used as sphere-equivalent diameter for a magnetic toner sample before being printed. Toner size distribution by volume is shown in Fig. 7. Particle size at 50 vol\% of toner before being printed (Fig. 7: original) was $8.7 \mu \mathrm{m}$ as mentioned in 2.1 , and the maximum diameter was $13.5 \mu \mathrm{m}$. The sphere-equivalent diameter of the black circles was calculated to be $396 \mu \mathrm{m}$ from their volume, which was calculated by multiplying the area of black circles to the thickness of the printed toner. The particle sizes at $50 \mathrm{vol} \%$ for toner samples disintegrated in undiluted kerosene and $1 \%$ kerosene emulsion were $280 \mu \mathrm{m}$ and $304 \mu \mathrm{m}$ respectively, which was almost the same as those for printed toner. The incidence of particles below $100 \mu \mathrm{m}$ was very low: $3.0 \%$ in undiluted kerosene and $0.4 \%$ in $1 \%$ kerosene, which indicates that most particles maintained the bond that was established when being printed and did not comminute into fine particles. It was assumed that particles disintegrated in

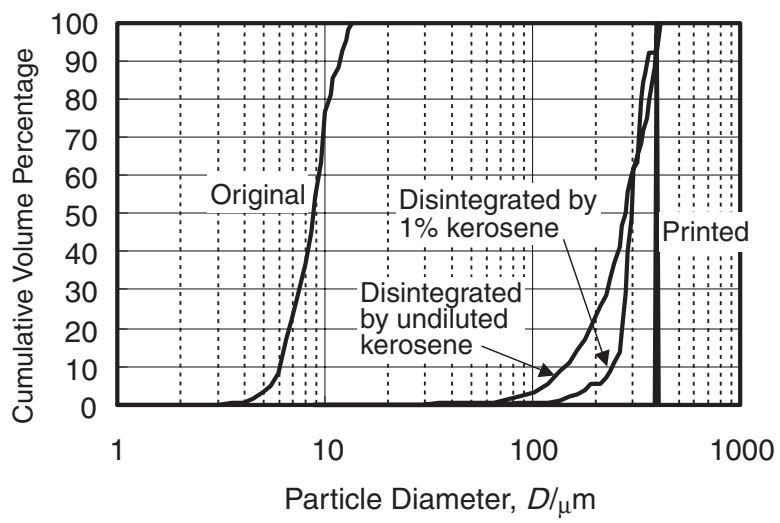

Fig. 7 Size distributions of original, printed, and disintegrated toner (magnetic)

undiluted kerosene were smaller than those done in $1 \%$ kerosene because the toner had already detached from the paper during the process of disintegration in sodium hydroxide solution, which led to little progress in the grinding by stirring.

\subsection{Bonding strength of coagulated toner by kerosene flocculant}

Augusta et al. ${ }^{9)}$ also investigated the use of kerosene or nheptane as a flocculant and reported them to be unsuitable for this deinking method because the bond between toner particles was insufficient to keep them from breaking. In their study, flocculant had been added at a rate of $2 \%$ of paper into $1 \%$ pulp; i.e., the flocculant concentration in water had been $0.02 \%$. From our previous results, ${ }^{2)}$ it is considered that toner cannot be softened at this kerosene concentration and would not yet show adhesive properties. So, bonding strengths of toner were examined for cases when kerosene was used as flocculants at concentrations of $0.02 \%, 1 \%$, and without dilution. Also, the bonding strength was measured between magnetic and nonmagnetic sample tablets that were put into 1-octadecanol and had been cooled down in order to solidify after being heated to $70^{\circ} \mathrm{C}$. The relationship between pressure and pulling stress (bonding strength) of magnetic and non-magnetic sample tablets is shown in Fig. 8. Each plot shows the average of five measurements. The results for samples soaked in kerosene were reproducible and the relationship between pressure and pulling stress was quite linear. Pulling stress increased with kerosene concentration: $10.4-15.5 \mathrm{kPa}$ and $20.4-36.4 \mathrm{kPa}$ for $1 \%$ kerosene and undiluted kerosene, respectively, while it was $2.9-3.9 \mathrm{kPa}$ for $0.02 \%$ kerosene. These results indicate that toner is softened only slightly with $0.02 \%$ kerosene, but adhesion increases kerosene concentrations over $1 \%$. Conversely, the results of soaking in 1-octadecanol are more scattered than the results for those in kerosene. It is regarded that the variation in adhesion in each measurement, which was larger than that of kerosene, influenced the results because 1octadecanol shows high stress, even with small amounts of 1octadecanol, compared to kerosene. The five results of each plot varied between $15-35 \mathrm{kPa}$, so the average was about $25 \mathrm{kPa}$ for each level of pressure. Since toner size and stirring conditions were different from the real process, and because 


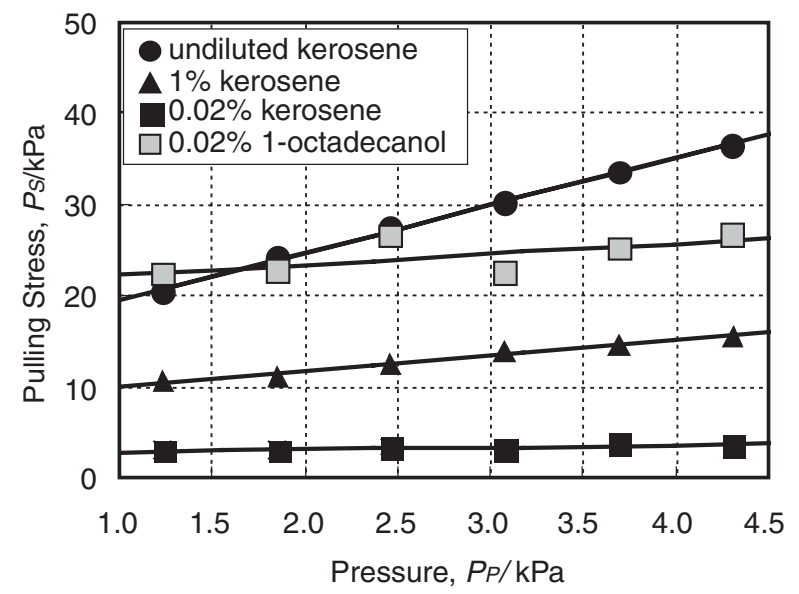

Fig. 8 Relation between pressure and pulling stress of magnetic and nonmagnetic toner samples.

the values depend on the smoothness of the toner surface, these absolute values could vary depending on conditions. However, relatively speaking, the pulling stress of 1octadecanol was 10 times higher than that of kerosene at the same concentration, which substantiates Augusta et al.'s description ${ }^{9)}$ of bonding strength. Using kerosene at concentrations over $1 \%$, the pulling stress was high, even at ambient temperature, because of its adhesion. In the case of $1 \%$ kerosene, the bonding strength was about half that of 1octadecanol, and in undiluted kerosene it was equal to or more than 1-octadecanol.

\subsection{Coagulation properties}

Model samples using magnetic and non-magnetic toner were disintegrated by the kerosene disintegration method and coagulated by stirring the mixtures after the addition of kerosene or 1-octadecanol as a flocculant. The size at 50 vol\% of coagulated toner is shown in Fig. 9. Particle size at $50 \mathrm{vol} \%$ of magnetic toner before being coagulated was $304 \mu \mathrm{m}$, as shown in 3.2. On the other hand, the particle size at $50 \mathrm{vol} \%$ of the coagulate made with $0.02 \%$ 1-octadecanol was $503 \mu \mathrm{m}$, which is about 4.5 times in volume ratio. Using

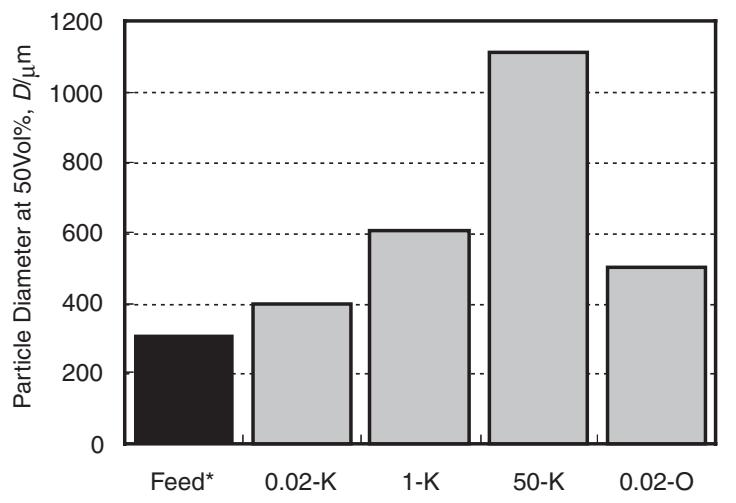

Fig. 9 Particle size of coagulated toner under several coagulating conditions. Feed*: Disintegrated sample prepared by kerosene disintegration of a printed sample using magnetic toner with $1 \%$ of kerosene. $0.02-\mathrm{K}$ : $0.02 \%$ kerosene. $1-\mathrm{K}$ : $1 \%$ kerosene. $50-\mathrm{K}$ : $50 \%$ kerosene. 0.02-O: $0.02 \%$ 1-octadecanol. kerosene of the same concentration as 1-octadecanol, the size at 50 vol\% was $397 \mu \mathrm{m}$ (2.2 times in the volume ratio) and both the size of coagulates as well as bonding strength with kerosene was smaller than that with 1-octadecanol. However, the size of coagulates increased with higher concentrations. The size at $1 \%$ kerosene was $602 \mu \mathrm{m}$ (7.8 times in volume ratio); at $50 \%$ kerosene it was $1,114 \mu \mathrm{m}$ (49.2 times in volume ratio), which means that the particle size at $50 \mathrm{vol} \%$ can exceed $1 \mathrm{~mm}$.

Next, coagulation properties of each coagulation reagent were investigated by separating magnetic and non-magnetic products with a neodymium-boron magnet. Figure 10 shows the deinking percentage (volume percent) by magnetic separation. The volume ratio of magnetic toner to total toner, which was calculated by the printed area of a model sample obtained in the previous paper ${ }^{2)}$ and the thickness of printed toner obtained in 3.1, is also shown in this figure. The volume ratio of magnetic toner to total toner, which can be calculated by the difference in toner densities (magnetic: $1.70 \mathrm{~g} / \mathrm{cm}^{3}$; non-magnetic: $1.05 \mathrm{~g} / \mathrm{cm}^{3}$ ) because these were mixed at $1: 1$ by weight, was $38.2 \%$. Therefore, it is suggested that coagulation occurred with every flocculant since deinking percentages were higher than $38.2 \%$. Coagulation proceeds with the increase in kerosene concentration, which in turn leads to an increase in the deinking percentage. The deinking percentage was only $57.2 \%$ with $0.02 \%$ kerosene, but reached $90.9 \%$ with $1 \%$ kerosene and $98.4 \%$ with $50 \%$ kerosene. Although the deinking percentage of $80.4 \%$ with $1-$ octadecanol was higher than that with kerosene of the same concentration, it was obviously lower than the deinking percentage when using kerosene over $1 \%$. The order of the deinking percentage corresponds with the size order of coagulates, which reveals that larger amounts of nonmagnetic toner could be recovered by a magnet if larger coagulates were produced.

According to the theoretical calculations of Augusta et al., ${ }^{9)}$ when the magnetic powder content in the coagulates was $6 \%$, the coagulates would have to have been about $1 \mathrm{~mm}$ in size in order to be recovered through resistance against inertia, even by using a $2 \mathrm{~T}$ magnetic separator (flow velocity: $0.1 \mathrm{~m} / \mathrm{s}$ ). Also, the coagulates would need to be about $500 \mu \mathrm{m}$

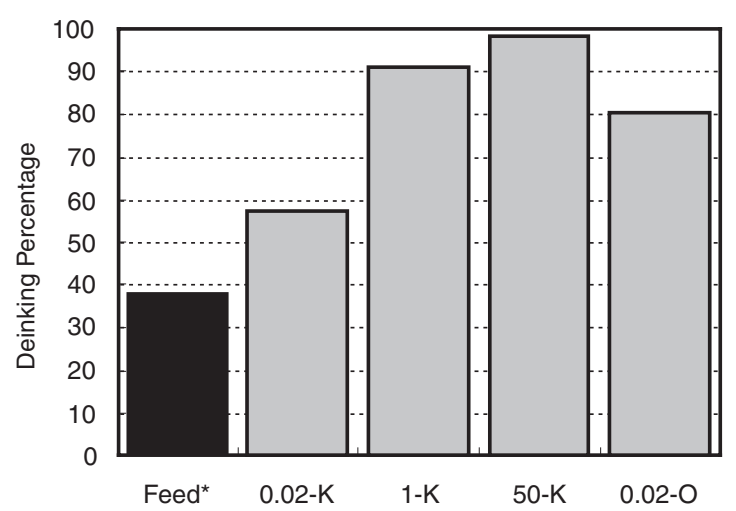

Fig. 10 Deinking rate by magnetic separation under several coagulating conditions. Feed*: volume $\%$ of magnetic toner of feed. $0.02-\mathrm{K}: 0.02 \%$ kerosene. 1-K: $1 \%$ kerosene. 50-K: $50 \%$ kerosene. 0.02-O: $0.02 \%$ 1octadecanol. 
in size at a magnetic powder content of $30 \%$ according to the relationships they illustrated. Since the ratio of magnetic powder to magnetic toner was $58 \%$ in the present study (see section 2.1), the ratio of magnetic powder to total toner by weight was about $29 \%$ in this experiment. Therefore, Fig. 9 suggests that the coagulates produced by all conditions except $0.02 \%$ kerosene satisfied their theoretical required sizes and could potentially achieve almost a $100 \%$ deinking percentage using a $2 \mathrm{~T}$ magnetic separator. Also, in the case of using kerosene at concentrations over $1 \%$, high deinking percentages are expected to be achieved even by a magnetic separator with a magnetic flux density lower than $2 \mathrm{~T}$. Although these results were obtained with a model sample printed with a black circle on, the probability of producing very fine particles is low, even for real waste paper, because toner is liberated in a range of sizes close to printed toner by this disintegration method. The sphere-equivalent diameter is about $70-100 \mu \mathrm{m}$, even when they are broken down widthand breadth-wise into $200-300 \mu \mathrm{m}$ sizes, which is considered to be the most highly grinded case for a character printed in 11 point font whose width is $200-300 \mu \mathrm{m}$. When figures and pictures are printed, liberation as larger particles is expected. Only a small amount of paper fiber was observed by microscope in the recovered samples. Although the exact amount could not be measured, the loss of paper is estimated to be less than $1 \%$. These results are led by advanced liberation of toner by the kerosene disintegration method, and it is suggested that advanced deinking could be achieved with a high level of paper recovery if paper straying into toner at the magnetic separator could be controlled.

It has been confirmed that coagulation of magnetic and non-magnetic toner is promoted by using over $1 \%$ kerosene as a flocculant, and that this improves deinking. Large and strong coagulates are formed at ambient temperature under this process. Although this method is expected to be an ideal deinking method for waste office paper, kerosene at concentrations higher than $1 \%$, which is a relatively large amount, is necessary for disintegration or coagulation. The actual consumption of kerosene in each process was not examined in this study, but non-reacted kerosene was observed after this process when kerosene concentrations over $1 \%$ were used. So, further examinations on the minimal amount of kerosene necessary and a kerosene recovery system will have to be conducted.

\section{Conclusion}

This study investigated the application of coagulates produced by a kerosene flocculant to magnetic deinking using waste office paper that was disintegrated by kerosene. The results are summarized as follows:
(1) The thickness of toner liberated by the kerosene disintegration method and that of printed toner was almost the same, although their appearances differed. Particle size at $50 \mathrm{vol} \%$ of liberated toner by the kerosene disintegration method carried out on model samples printed with magnetic toner was 280-304 $\mu \mathrm{m}$, which was similar to the value for printed toner, $396 \mu \mathrm{m}$.

(2) From an examination of the bonding strength between magnetic and non-magnetic toner soaked in kerosene (at ambient temperature) or 1-octadecanol $\left(70^{\circ} \mathrm{C}\right)$, the bonding strength with $0.02 \%$ kerosene was found to be one-tenth of that of 1-octadecanol at the same concentration However, the bonding strength was almost equal to that of 1-octadecanol, even at ambient temperature, when kerosene was used at concentrations over $1 \%$ because adhesion increased from the softened toner.

(3) Model samples using magnetic and non-magnetic toner were disintegrated by the kerosene disintegration method and coagulated by stirring the mixtures after the addition of kerosene or 1-octadecanol as a flocculant. The particle size at $50 \mathrm{vol} \%$ of coagulates made with kerosene over $1 \%$ was larger than coagulates made with $0.02 \% 1$-octadecanol. The size was over $1 \mathrm{~mm}$ with $50 \%$ kerosene. When these were recovered by a $0.45 \mathrm{~T}$ neodymium-boron magnet, deinking percentages were $80.4 \%$ with $0.02 \%$ 1-octadecanol, $90.9 \%$ with $1 \%$ kerosene, and $98.4 \%$ with $50 \%$ kerosene. Large and strong coagulates could be produced and a high deinking percentage achieved by using kerosene over $1 \%$ as a flocculant.

\section{REFERENCES}

1) Ministry of international trade and industry: Kami Parupu Tokei Nompo (1998).

2) T. Oki, S. Owada, H. Yotsumoto and H. Tanuma: J. Mining Mat. Proc. Inst. Jpn. 118 (2002) 179-184.

3) F. Julien and S. Amand: Int. J. Min. Proc. 56 (1999) 277-316.

4) S. Endoh and Y. Oikawa: Paper Pulp tech. 39 (1) (1988) 1-11.

5) K. Masamizu, J. Egawa, M. Hagiwara and N. Fukagai: Jpn. Tappi J. 50 (10) (1996) 14-20.

6) M. Kemper: Int. J. Min. Proc. 56 (1999) 317-333.

7) Nippon Nyukazai Co., Ltd: Pulp Paper Research Times (1990) 38-39.

8) G. M. Gubitz, S. D. Mansfield, D. Bohm and J. N. Saddler: J. Bio. Tech. 65 (1998) 209-215.

9) M. Augusta, D. Azevedo and D. Miller: Tappi J. 83 (2000) 66-72.

10) D. Azevedo, D. Miller and W. Chamblee: Tappi 1997 Recycling Sympo. Proc. (1997) 387.

11) T. Oki, S. Owada, H. Yotsumoto and H. Tanuma: Resources Proc. 48 (1) (2001) 27-36.

12) T. Oki, S. Owada, H. Yotsumoto and H. Tanuma: Progress in Paper Recycling 10 (3) (2001) 25-35.

13) A. Synder and J. C. Berg: Tappi J. 77 (1994) 79-84 (Reference in the Augusta et al.'s report ${ }^{9)}$ ). 